\title{
Firms' Participation on Grand Ethiopian Renaissance Dam Construction in Ethiopia
}

\author{
Zenaye Degefu* (Lecturer, PhD Fellow) \\ School of Business and Economics, Oromia State University \\ Degye Goshu (PhD, Associate Professor) \\ Senior Researcher, Ethiopian Economics Association
}

\begin{abstract}
This study designed particularly to identify factors affecting firms' decisions on the purchase of bonds and the amount of their investment on bond purchase for GERD construction. This study used cross-sectional data of enterprise surveys collected by the World Bank in 2015. In addition to descriptive statistics, the Tobit model was estimated to identify the underlying factors that; determine both firms' participation in the purchase of bonds and the amount of their investment for GERD construction. The model result indicates that the expected value of the amount of bond purchase is 2593.71 birr with $50.1 \%$ likelihood of the firms to purchase the bond for GERD construction. The results from the Tobit model indicate that; the decision to purchase bonds and the amount of bond purchase for GERD construction was affected by adopting technologies, being local owner, the income of firms, receiving loan, number of employees, the existence of female owner and being large in business size. The result suggests the need to design interventions to increase the access of innovative technologies by offering at a reasonable price and increase the access of a loan by reducing collateral requirements and avoiding complex bureaucratic processes to receive the loan. Besides, it is good if the government and the non-government organization works to empower women to be the owner of firms; and help firms to utilize their potential that leads them to hire more employees, produce high profit and be larger in its size.
\end{abstract}

Keywords: GERD, Tobit, Bond, Firms, Ethiopia

DOI: $10.7176 / \mathrm{JAAS} / 76-03$

Publication date:October $31^{\text {st }} 2021$

\section{INTRODUCTION}

Ethiopia is a landlocked country in the Horn of Africa with over 114 million population, which makes the country the 2nd-most populous in Africa (ADB, 2021). In 2020, the service and agriculture sector takes a relatively larger share of Ethiopian GDP that is $36.9 \%$ and $33.9 \%$, respectively. The dependency of one country on the production and export of primary commodities cannot be sustained in the face of a changing global context. Thereby, the manufacturing and industry sector should take the leading role to realize the development of one country. However, in Ethiopia, the manufacturing and industrial sector gives a modest contribution to the country's GDP (24.8\%) and occupation (9\% of the workforce). The major industries are food processing, beverages, textiles, leather, garments, chemicals, metals processing, and cement (WB, 2021).

Industry and manufacturing have been the driver of economic growth, structural change, and catch-up state and it is considered as a cornerstone of many national economies that generates productive jobs and sustainable economic growth. Manufacturing has multiplier effects and closely related to other sectors of the economy (Naudé and Szirmai, 2012 and Warren, 2013). According to Veugelers (2013), these links can be both backward (such as with mining or construction), or forwards (such as with transportation, wholesale and retail trade, and business services). The increasing demand for manufacturing stimulates the creation of jobs, investments, and innovations (Westkämper, 2014).

Even if the manufacturing and industry sectors contribute to the development of one country, it is identified that power shortage and electric power interruption were at the top of major constraints for their development in Ethiopia (UNDP, 2017). To overcome this problem, the government Ethiopia start to contract GERD in 2011, which is one of the hydropower electric sources of the country. Hydropower is a basis of clean, sustainable, and renewable energy. It has a contribution to reducing carbon emissions and maintaining environmental sustainability. In Ethiopia, it is the major source of electricity (Handiso, 2018).

When completed, GERD will be the largest hydroelectric power plant in Africa (10th in the World) with over 6000MW capacity. The Dam will increase Ethiopian's installed power generation capacity by $200 \%$. With 45,000 MW hydropower potential, Ethiopia aspires to install 37,000 MW of electricity by 2037 and become a major power exporter. In the medium term, Ethiopia could generate US\$1 billion foreign currency from power export, and reduce Ethiopia's dependence on imported petroleum (Makonnen, 2016).

\subsection{Statement of the problem}

Even if Ethiopia's economy experienced strong and broad-based growth with a real GDP growth rate of 9\% in 
2018/19; Ethiopia has been confronted by multidimensional poverty and one of the poorest nations with a per capita income of $\$ 850$ (WB, 2020). In the modern world, energy is the determinant factor of economic activities and human quality of life; however, Ethiopia has been faced with energy poverty those who the most energy consumers are dependent on traditional primary sources (IEA, 2017). Since Ethiopia is rich in natural resources, including water to produce energy, it has the potential to minimize the threat through an integrated multipurpose development process. In this regard, hydropower has a significant role to reduce energy poverty and enhance the multipurpose use of natural resources efficiency.

Ethiopia has embarked on an ambitious strategy of industrialization, and the generation of abundant and affordable electricity is crucial to this endeavor. Consequently, the government of Ethiopia launched different multipurpose hydropower plant projects. The Grand Ethiopian Renaissance Dam, which is one of the multipurpose dams particularly for the sustainable energy-water-food-ecosystem service nexus at the national level (Handiso, 2018).

The GERD is estimated to cost close to 5 billion US dollars that is about 5.2\% of the 2019 Ethiopian GDP. Since there is a lack of international finance for projects on the Blue Nile River, Ethiopia is forced to finance the construction of GERD with crowdfunding through internal fundraising in the form of selling bonds for firms and persuading employees to contribute a portion of their incomes. The successful completion of GERD without explicit support from western financial institutions; will have a significant impact on changing world bad perceptions about Ethiopian backwardness. In this regard, as of March 2016, the business sector contributes $16 \%$ of the total bond purchase which is equivalent to 1,600,000,000 (GERD Council, 2016).

Purchasing bonds are one type of financial investment since bonds are typically securities issued by a corporation or governmental body for a specified term that become due for payment at maturity when the par value/ face value of the bond is returned to the investors. When the investors buy bonds, he or she becomes a creditor of the issuer. The buyer does not gain any kind of ownership rights to the issuer, unlike in the case with equity securities. Likewise, GERD bonds avail for all societies with 5 years of maturity and a 5.5\% interest rate. In this study, it is going to identify factors that affect investment decision of firms on bond purchase for GERD construction and amount of their investment that expressed in monetary term.

Even if the construction of GERD reached $75 \%$ of its completion, since it does not have an allocated budget for construction and finical support international financial sources, it is important to identify factors that hider firm's participation investment on bond for GERD contraction. Knowing this factors help government and other concerned bodies to intervene and undertake corrective action to stimulate the purchase of bond for GERD construction and other mega projects to bring development with in the country.

\subsection{Objective of the Study}

The general objective of this study was to identify the determinants of firms' participation on GERD construction in Ethiopia

The specific objective of was

1. To assess factors affecting firms participation in purchase of bond for GERD construction in Ethiopia

2. To identify determinates of amount of bond purchase for GERD construction in Ethiopia

\section{RESEARCH METHODOLOGY}

\subsection{Description of GERD}

The Grand Ethiopian Renaissance Dam is a gravity dam on the Blue Nile River in Ethiopia which is under construction since 2011. The dam is in the Benishangul-Gumuz Region of Ethiopia, about $45 \mathrm{~km}$ east of the border with Sudan. The primary purpose of the dam is electricity production to relieve Ethiopia's acute energy shortage and for electricity export to neighboring countries. With a planned installed capacity of 6.45 gigawatts, the dam will be the largest hydroelectric power plant in Africa when completed, as well as the $10^{\text {th }}$ largest in the world.

Filling the reservoir has begun in July 2020 and it will take between 5 and 15 years to fill with water, depending on hydrologic conditions during the filling period and agreements reached between Ethiopia, Sudan and Egypt. Ethiopia initiated to construct the Grand Ethiopian Renaissance Dam in 2011, and the reactions from the lower riparian countries range from a threat of war-based opposition to official avowals of support. The GERD is a project not supported by all parties. IMF has raised concerns as to the amount of domestic financing being absorbed into a single project; they have expressed a general concern considering the Ethiopian development plan (Davidson, 2012). 


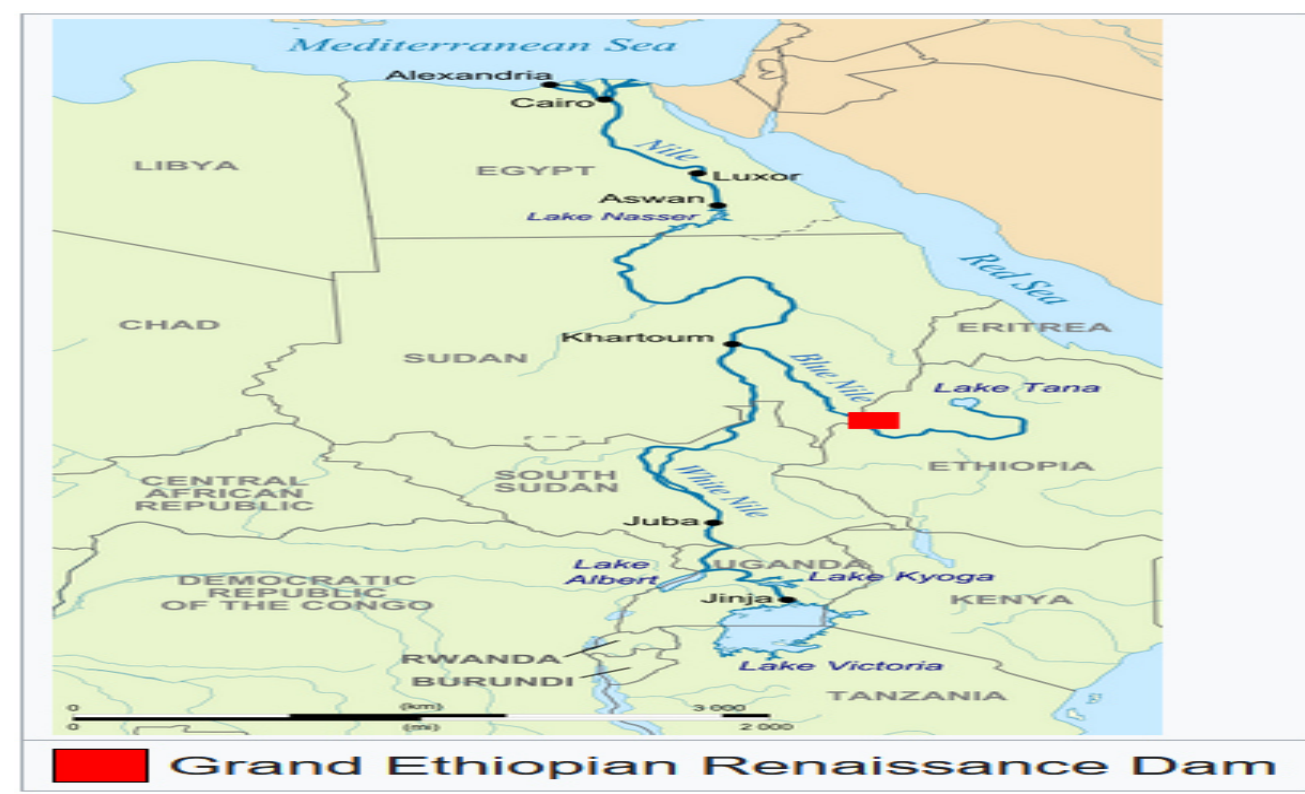

Figure 1: Map of Ethiopia and GERD

\subsection{The Data}

This study is based upon an Ethiopian enterprises survey collected by World Bank in 2015. The sample was selected using stratified random sampling. Three levels of stratification were used in this country: Industry, establishment size, and region. Industry stratification was designed in the way that follows: the universe was stratified into four manufacturing industries (food and Beverages, textile and garments including leather, nonmetallic mineral products, and other manufacturing), and three services sectors (transportation, retail, and other services). Size stratification was defined as follows: small (5 to 19 employees), medium (20 to 99 employees), and large (more than 99 employees). Regional stratification for the 2015 Ethiopia enterprises survey was done across six geographic regions: Addis Ababa and Dire Dawa city administrations, and Amhara, Oromia, SNNPR, and Tigray regional states.

\subsection{Method of Data Analysis}

To analyze the data, both descriptive statistics and an econometric model were used. Student t-test and Chisquare tests were used to summarize characteristics of sample firms among bond purchaser and non-purchaser and the Tobit econometric model was employed to identify determinants of the participation in the bond purchase and amount of bond purchased by firms for GERD construction. The analyzed data were presented by using tables and figures.

\section{Model Specification}

To estimate the factors associated with the firms' participation in bond purchase for GERD construction and the amount of bond purchase for GERD; a Tobit regression model was used. Tobit model was used when the dependent variable is censored, using OLS yields biased and inconsistent parameter estimates. This bias comes from the fact that considering only the observable sample and ignores the others, there is no guarantee that the expected value of the error term will be necessarily zero. For this reason, the OLS model is becoming less frequently used except as a basis for comparison to some other more appropriate models (Wooldridge, 2002; Verbeek, 2004 and Greene, 2012).

Following (Tobin, 1958 and Greene, 2012) the simplest Tobit regression model, when the distribution of the estimated amount of bond purchase censored from the left at the value of 0 , was conceptualized to identify which variables have a greater likelihood of affecting the bond purchase status of the firms in the Ethiopia. This model has been extensively used to determine the effect of explanatory variables on the probability of being purchase bonds for GERD (MacDonald and Moffit, 1980; Asoga, 2012). The model can be written as follows:

$$
\mathrm{Y}_{\mathrm{i}}=\max \left\{\mathrm{y}_{\min }, \mathbf{X}_{\mathrm{i}} \boldsymbol{\beta}+\varepsilon_{\mathrm{i}}\right\}
$$

where is the observed value of the dependent variable, in this case, the amount of bond purchase for GERD, denotes the threshold value, in this case, zero, is a $1 \mathrm{xK}$ vector of exogenous variables with a corresponding coefficient vector $\mathrm{b}$ and is a zero-mean, independently and identically distributed normal random disturbance. The parameter estimates can be obtained using maximum-likelihood estimation (MLE).

Interpreting the coefficient of Tobit model in the same way as OLS or uncensored regression models may 
be meaningless. Therefore, it is a must computing the derivatives of the estimated Tobit to predict the effects of change in the explanatory variables. Following McDonald and Moffitt (1980) the expected amount of bond purchase $\mathrm{E}(\mathrm{y})$ is

$$
\mathrm{E}(\mathrm{y})=\mathrm{x}_{\mathrm{i}} \beta \Phi(\mathrm{z})+\sigma \varphi(\mathrm{z})
$$

Where $X_{i}$ is a vector of explanatory variables, $\Phi(z)$ is the cumulative distribution of $\mathrm{z}$, where $\mathrm{z}$ is equal to $\frac{X_{i} \beta}{\sigma}$

$\sigma \varphi(Z)$ is the value of the derivative of the normal curve at a given point (i.e. normal density), $\mathrm{Z}$ is the $\mathrm{Z}$ score for the area under normal curve, $\beta$ is the vector of Tobit maximum likelihood estimates and $\sigma$ the standard error of the error term.

McDonald and Moffitt (1980) proposed the following techniques to decompose the effects of explanatory variables into the firms' participation in the bond purchase and amount of bond purchase for GERD construction. This means a change has two effects; one it affects the conditional mean of y in the positive part (bond purchase) of the distribution. Second, it affects the probability that the observation will fall in the part of the distribution. The marginal effect of an explanatory variable on the expected value of the dependent variable is given by:

$$
\frac{\partial \mathrm{E}\left(\mathrm{y}_{\mathrm{i}}\right)}{\partial \mathrm{x}_{\mathrm{i}}}=\Phi(\mathrm{z}) \beta, \text { where } \quad \mathrm{Z}=\frac{\beta \mathrm{x}_{\mathrm{i}}}{\sigma}
$$

The change in the status of bond purchase as exogenous variable xi changes is given by:

$$
\frac{\partial \Phi(Z)}{\partial x_{i}}=\frac{\varphi(z) \beta}{\sigma}
$$

The change in the amount of bond purchase with respect to change in explanatory variables among bond purchaser firms given by:

$$
\frac{\partial \mathrm{E}\left(\mathrm{y}_{\mathrm{i}} / \mathrm{y}_{\mathrm{i}}^{*}>0\right)}{\partial \mathrm{x}_{\mathrm{i}}}=\beta_{\mathrm{i}}\left(1-\mathrm{Z} \frac{\varphi(\mathrm{Z})}{\Phi(\mathrm{Z})}-\left(\frac{\varphi(\mathrm{Z})}{\Phi(\mathrm{Z})}\right)^{2}\right)
$$

Before analyzing the Tobit model result, test of model fitness and normality was made and adjustments are carried out accordingly.

\section{RESULT AND DISCUSSION}

This part of the paper presents the results of statistical analyses; and the discussions based on the secondary data generated through the Enterprise survey by World Bank in 2015. This study compromises 759 firms found in Ethiopia. Out of the total respondents, 44.4\% were purchase bonds for GERD construction and only $8.96 \%$ were with a female top manager. Of the total respondents, $88.14 \%$ were male while the remaining $11.96 \%$ were female (Table 2).

Table 1: Characteristics of Firms

\begin{tabular}{llll}
\hline Variables & No (\%) & Yes (\%) & Total \\
\hline Sex of respondent (Male) & $90(11.86)$ & $669(88.14)$ & 759 \\
\hline Female top Manager & $691(91.04)$ & $68(8.96)$ & 759 \\
\hline Purchase Bond & $422(55.6)$ & $327(44.4)$ & 759 \\
\hline
\end{tabular}

Source: Own computation, 2021

Figure 2 below shows the region of establishment and it is indicated that the majority (54\%) of sampled firms found in Addis Abeba which capital city of Ethiopia. This may be due to infrastructural facilities found in the capital city that contribute to the success of one firm (Baye et al., 2005). 


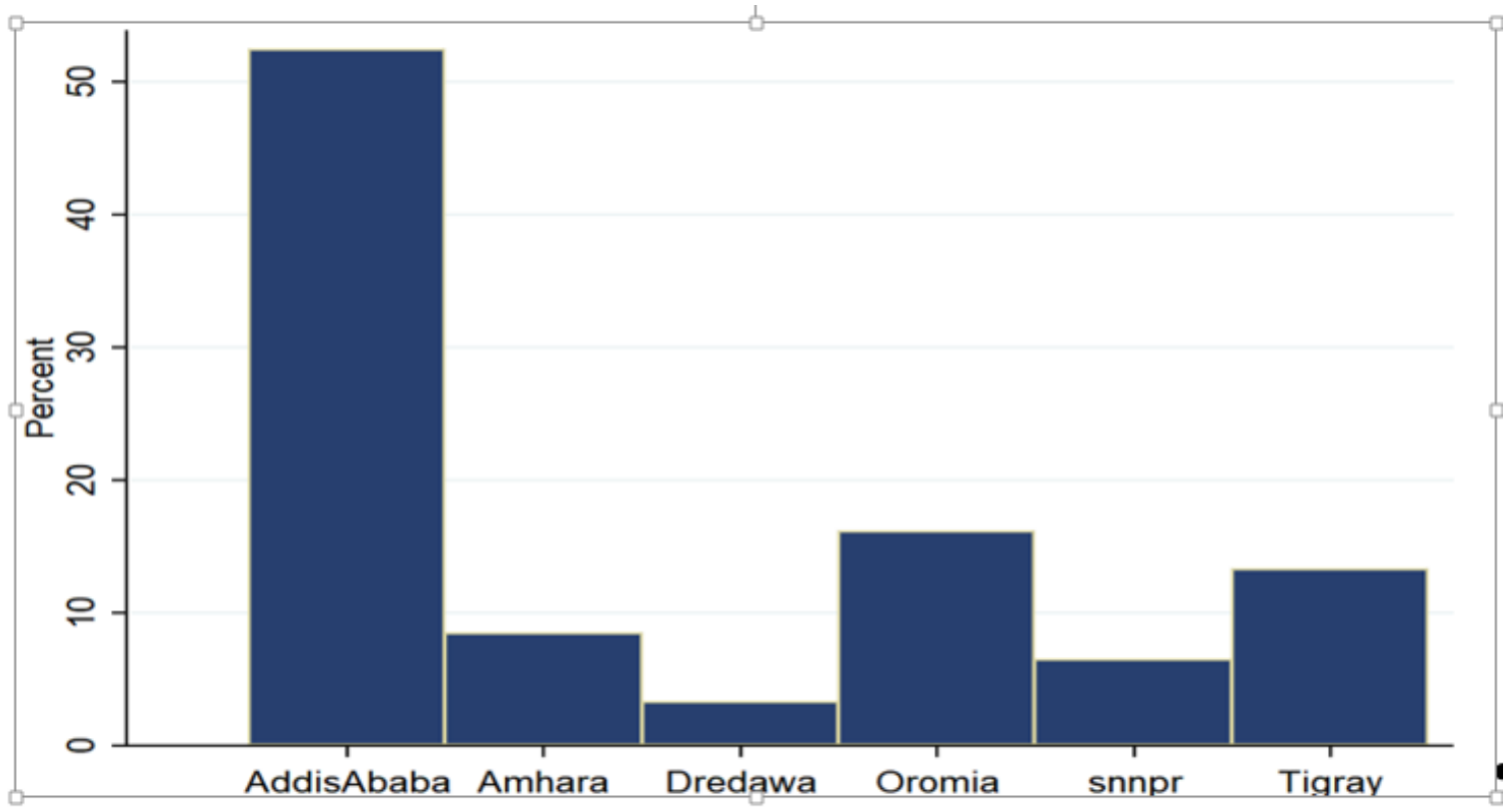

Figure 2: Region of Establishment (Location of firm)

\subsection{Participation in GERD Bond Purchase and Characteristics of Firms}

Table 3 below presents the t-test and chi-square comparison of means of selected variables by firms' participation in the purchase of bonds for GERD construction for the sampled 759 firms. Some of these characteristics are explanatory variables of the estimated Tobit models to identify determinates of the amount of bond purchase for GERD construction.

Having an international certificate is very important for a business organization as it ensures quality and safety in both products and services of international trade. Of the total respondents, only $6.98 \%$ have an international certificate; of which only $10.39 \%$ were bond purchase for GRAD construction which is significantly higher than non-purchaser. Around $44.40 \%$ of total firms engaged in the manufacturing sector, while the remaining involves in the construction and service sector and there is no significant difference between the bond purchaser and non-purchaser in this regard. Regarding the legal status of firms, only $3.95 \%$ are share companies while $45.59 \%$ and $50.46 \%$ are partisanship with private limited companies and sole proprietorship respectively.

Having a robust online presence by having an organizational website makes firms profitable through generating more revenue (Brynjolfsson, 2000 and Chen and Hsu, 2009). However, only 29.91\% of sample firms have their website, of which only $32.64 \%$ of them participate in bond purchase for GERD construction. The average number of employees that indicate the extent of organizational capacity utilization in sampled firms is 89.97; that is significantly larger for bond purchase that is 133.06 .

Adoption of innovative technologies is necessary to increase firms' productivity and profitability (Tushman and O'Reilly, 2002; Ekvall and Arvonen, 1994 and Howell and Higgins, 1990). Of the total sampled firms, $36.36 \%$ were adopters of innovative technologies, of which $44.21 \%$ were bond purchasers that are significantly better than non-purchaser. Around $52.44 \%$ of sampled firms were established and operate in the capital city of Ethiopia; which is favored by its infrastructural facilities and nearness to federal office. The finding of this study indicates that $89.46 \%$ of the total sampled firms were fully owned by local or domestic investors, which is significantly larger for the bond purchaser (Table 3).

Facing informal competition is a challenge for legally registered firms since informal businesses are firms that do not register with and sell their products with the authorities for tax, benefit, and labor law purposes when they should do so (Williams et al., 2017). Among the sampled firms, 35.70\% face informal competition, and there is no significant difference between the bond purchaser and non-purchaser.

Being female business owner positively contribute for investment in the safest sector; as the bond is one of the safest investment, particularly, municipality bond which provided by the government for public investment. In this study, $36.50 \%$ of sampled firms have female shares in ownership which is significantly larger for the bond purchaser. The other important variable is firm age which is an important variable since it affects a firm's productivity because of the cumulative experience (Abayie et al., 2011 and Kipesha, 2013). In the study, firms are with an average age of 13.86 years that is significantly higher for the bond purchaser that is 15.08 years.

Large size firms have is that typically, they are more established and have greater access to funding. They 
also enjoy more sustained business, which generates higher sales and larger profits than micro and smaller-scale businesses. In this study, $48.75 \%$ of the total respondents are medium and large in size of their business, and bond purchaser firmer are significantly medium and large-scale firm owners.

Getting a loan is an important factor for the success of firms since finance is one of the factors of production and it is positively correlated with the investment decision of firms (Ndikumana, 2014 and Ghura and Goodwin, 2000). Here in this study, $41.50 \%$ of firms receive loans from the financial institution which is significantly higher for bond purchasers at 1\% level of statistical error. Engaged in export is also important for firms as it connects them with an international marker at a relatively better price. However, in this study, only $10.41 \%$ of firms export their product, and bond purchasers are significantly better with their export. The sampled firms are with an average $\ln$ of income of 15.39 and bond purchasers are significantly better with their income than non-purchaser at $1 \%$ level of statistical error. The average amount of bond purchase for GERD construction among bond purchasers is 3,151,785 in Ethiopian birr (Table 3).

Table 2: Summary of Variables compared between Bond Purchaser and Non-Purchaser

\begin{tabular}{|c|c|c|c|c|}
\hline Variables & $\begin{array}{l}\text { Non-bond } \\
\text { purchaser }\end{array}$ & Bond purchaser & $\begin{array}{l}\text { t-value/ } \\
\text { chi2 }\end{array}$ & Total \\
\hline International certificate (\% Yes) & 4.27 & 10.39 & $10.80 * * *$ & 6.98 \\
\hline Sector(\% manufacturing) & 43.36 & 45.70 & 0.4129 & 44.40 \\
\hline Own website $(\%$ Yes $)$ & 27.73 & 32.64 & 2.1599 & 29.91 \\
\hline Income $(\ln )$ & 15.085 & 15.790 & $-4.4060 * * *$ & 15.398 \\
\hline Amount of employee & 55.56 & 133.06 & $-2.7442 * * *$ & 89.97 \\
\hline Adopt innovative technology $(\%$ Yes $)$ & 30.09 & 44.21 & $16.1409 * * *$ & 36.36 \\
\hline Operate in capital city $(\%$ Yes $)$ & 51.90 & 53.12 & 0.1118 & 52.44 \\
\hline Local owner (Percentage) & 87.68 & 91.69 & $3.2012 *$ & 89.46 \\
\hline Face informal competition (\%Yes) & 33.89 & 37.98 & 1.3693 & 35.70 \\
\hline Female owner (\% Yes) & 32.46 & 41.54 & $6.6633 * * *$ & 36.50 \\
\hline Firms Experience & 12.89 & 15.08 & $-2.4542 * * *$ & 13.86 \\
\hline Business size $(\%$ of large $)$ & 42.65 & 56.38 & $14.1289 * * *$ & 48.75 \\
\hline Amount of bond purchase in Birr & 0 & 7098530 & $-1.3377 *$ & 3151,785 \\
\hline Export (\% Yes) & 8.29 & 13.06 & $4.5575 * *$ & 10.41 \\
\hline Loan (\% Yes) & 30.33 & 55.49 & $48.84 * * *$ & 41.50 \\
\hline Legal status of firm & & & 3.3433 & \\
\hline$\%$ of Share company & 4.03 & 3.86 & & 3.95 \\
\hline$\%$ of Partnership and PLC & 42.65 & 49.26 & & 45.59 \\
\hline$\%$ of Sole proprietorship & 53.32 & 46.88 & & 50.46 \\
\hline
\end{tabular}

$* * *, * *$ and $*$ is significant at $1 \%, 5 \%$ and $10 \%$ level of statistical error

Source: Own computation, 2021

\subsection{Firms' Participation in Bond Purchase for GERD Construction}

To identify determinates of the firms' participation in GERD construction by purchasing bonds and amount of bond purchase for GERD construction, the Tobit model was estimated. Potential explanatory variables were identified using different individual tests and stepwise regression. Here, the log-likelihood ratio test was made, which was used in the Likelihood Ratio Chi-Square to test whether all predictors' regression coefficients in the model are simultaneously zero. The test result rejected the null hypothesis that all the 10 variables regression coefficients are simultaneously equal to zero at less than one percent statistical errors. Therefore, it is possible to conclude that at least one exogenous variable significantly affects the firms' participation and amount of bond purchase for GERD construction (Table 4).

The second test carried out was a test of normality. This test was used to assure the assumed normal distribution of error terms. The test was made using an informal test of the normal probability plot of the residual. The test result confirmed that the residual or the error term is approximately normally distributed. Therefore, the assumption of the Tobit regression model, normality of the error term was fulfilled. This finding suggests that as there is no risk of estimating the model to identify firms' participation in the bond purchase and the amount of their investment for GERD construction using it (see Figure 3). 


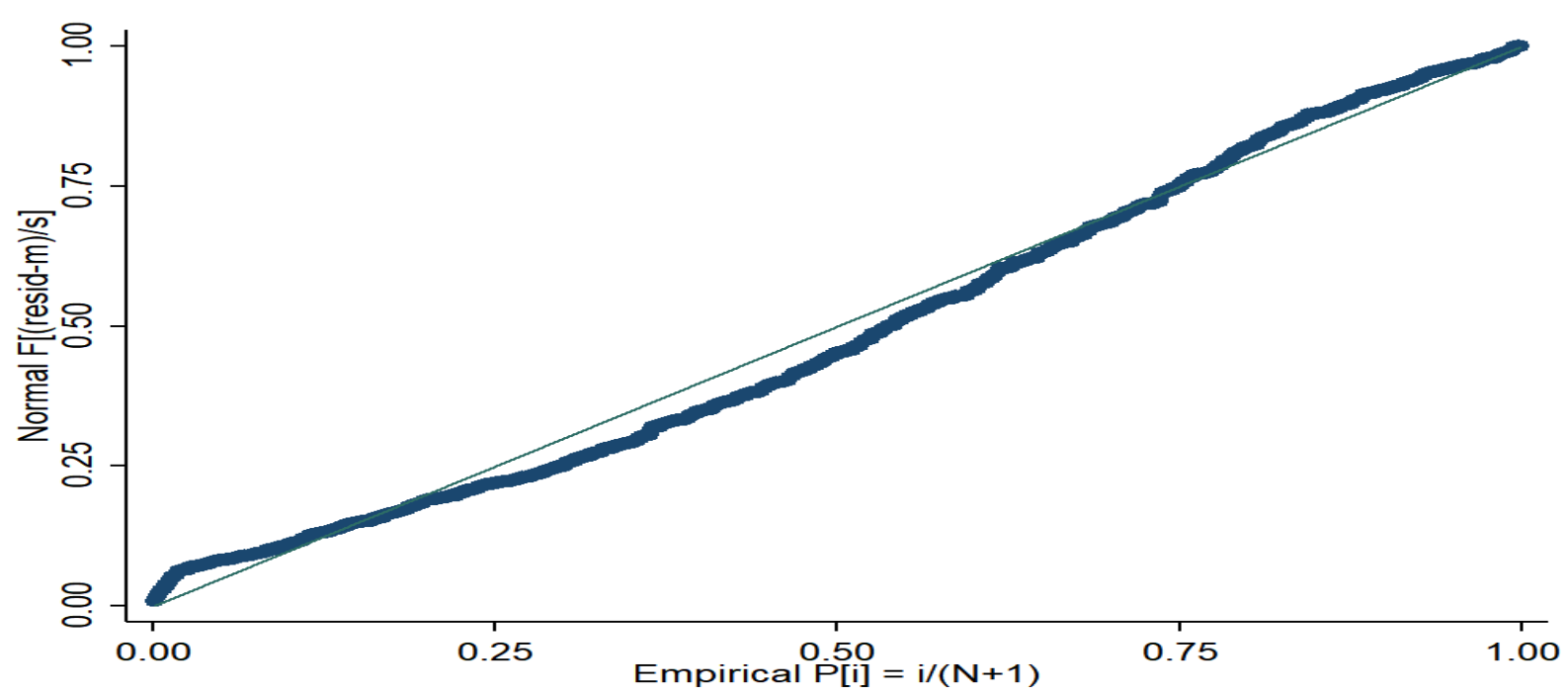

Figure 2: Normal probability plot of the residual of Tobit Model

Source: Own Computation, 2021

The Tobit model result suggests that out of 10 explanatory variables, seven variables were found to be statistically significant in explaining firms' decision to purchase and amount of bond for GERD construction. The variables which have a significant relationship with the decision to purchase bonds and amount of bond purchase were adopting technologies, being local owner, the income of firms, getting a loan, the number of employees, existence of female owner, and being large in business size (Table 4). The model result indicates that the expected value of the amount of bond purchase is 2593.71 birr with $50.1 \%$ likelihood of the firm to purchase the bond for GERD construction.

Local Owner: this variable was found to affect the amount of bond purchase and decision to purchase bond positively since GERD is a megaproject that does not have support from any foreign financial sources (Davidson, 2012), it is planned to construct the dam by raising fund through selling bonds to local community and firms. One unit increase in the percentage of local owner results raises the amount of bond purchase and bond purchase decision for GERD construction by $2.2 \%$ and $0.24 \%$ respectively at $1 \%$ level of statistical errors. This may be because GERD is the way that local owners express their nationalism and having this dam will reduce their electric power shortage and alleviates poverty by adjusting the macroeconomic problem of the country.

Adoption of Technologies: adoption of innovative technologies was found to affect both the amounts of bond purchase and decision to purchase the bond for GERD construction positively at $5 \%$ level of statistical error. Compared to a non-adopter, being an adopter raises the amount of bond purchase by $67.2 \%$ and $7.3 \%$ of the likelihood of decision to purchase the bond for GERD construction. This is since the adoption of innovative technologies expected to increase and productivity of firms that positively correlate with investment (Tushman and O'Reilly, 2002; Ekvall and Arvonen, 1994 and Howell and Higgins, 1990).

Female owner: this variable was found to affect the amount of bond purchase and decision to purchase the bond for GERD construction positively at $5 \%$ level of statistical error. Being a female business owner increase the amount of bond purchase for GERD by $62.5 \%$ while the decision to purchase a bond raised by $6.8 \%$. This may be due to women's preference for low-risk investments since bond purchase is one of the safest ones. This finding is in line with Powell and Ansic (1997) and Steinerock (1991) in Gaur et al, 2011 confirmed that women had a lower risk preference in their investment decision.

Firms Income: The income of firms is an important variable that positively and significantly contributes to the amount of bond purchase and decision to purchase bonds for GERD construction. The result of Tobit model estimation indicated that; a one percent increase in income of firms increases the amount of bond purchase and the decision to purchase bond by $24.8 \%$ and $2.7 \%$, respectively, at $1 \%$ level of statistical error. As firms' income increases, the amount of their saving increase and investment is sacrifices of saving for having a benefit in some future time. This finding is in line with Dawit (2010) that indicates as it is important to maintain good accounting records by firms to invest more.

Loan: A loan is an important source of financial resources for business and it is positively correlated with the investment of firms since it is the blood of any business activity and used to satisfy the financial gap of firms to run their business smoothly. This variable was found to affect both the amount of bond purchase and decision to purchase bonds for GERD construction positively and significantly, at $1 \%$ level of statistical error. The one who receives a loan to run their business increase the amount of bond purchase and decision to purchase bond $71 \%$ and $18.13 \%$, respectively. This finding is in line with the finding of Ndikumana, 2014 and Ghura and Goodwin, 
2000 .

Number of Employees: this variable is found to enhance both the amount of purchase and decision to purchase the bond for GERD construction at 5\% level of statistical error. A unit increase in the number of workers will increase the amount of bond purchase by $0.1 \%$ while it affects the decision to purchase the bond for GERD construction $0.01 \%$. This is due to the fact that the number of employees indicates the extent of organizational capacity utilization; increasing the amount of labor leads to reducing the workload per employee and reduces the likelihood of making errors or cut corners in performing their tasks, which contribute to the profitability of firms ((Fisher et al., 2006 and Oliva and Sterman, 2001).

Firm size: Having large firms was found to affect both amounts of bond purchase and decision to purchase bond positively and significantly at $10 \%$ level of statistical error. Compared to micro and small, being large businesses increase the amount of bond purchase and decision to purchase the bond for GERD construction by $66.1 \%$ and $7.34 \%$, respectively. This may because the size of a firm plays an important role in determining the kind of relationship the firm enjoys within and outside its operating environment. This result is in line with the findings of Kipesha (2013) and Dogan (2013) who confirm the positive contribution of firm size for investment.

Table 3: Estimation result of Tobit model

\begin{tabular}{|c|c|c|c|c|}
\hline Variables & Coefficient & Std error & $\begin{array}{l}\text { Change among } \\
\text { bond purchaser } \\
\mathrm{ME}=7.86\end{array}$ & $\begin{array}{l}\text { Change in } \\
\text { Probability } \\
\mathrm{ME}=0.501\end{array}$ \\
\hline Local owner(percentage) & $0.060 * * *$ & 0.018 & $0.022 * * *$ & $0.0024 * * *$ \\
\hline Adopt technology & $1.817 * *$ & 0.869 & $0.672 * *$ & $0.0735 * *$ \\
\hline Operate in capital city & -0.484 & 0.896 & -0.176 & -0.0196 \\
\hline Age of firm in year & 0.013 & 0.035 & 0.005 & 0.0005 \\
\hline Share of female owner & $1.693 * *$ & 0.860 & $0.625 * *$ & $0.0685 * *$ \\
\hline Face informal competition & 1.404 & 0.859 & 0.517 & 0.0569 \\
\hline Income $(\ln )$ & $0.680 * * *$ & 0.261 & $0.248 * * *$ & $0.0276 * * *$ \\
\hline Loan & $4.576^{* * *}$ & 0.879 & $1.710 * * *$ & $0.1837 * * *$ \\
\hline Number of Employee & $0.002 * *$ & 0.001 & $0.001 * *$ & $0.0001 * *$ \\
\hline Business size( $1=$ large or medium $)$ & $1.814^{*}$ & 1.075 & $0.661 *$ & $0.0734 *$ \\
\hline Constant & $-20.64 * * * 6$ & 4.233 & & \\
\hline Sigma & $9.840 * * *$ & 0.440 & & \\
\hline Log likelihood & -1520.70 & & & \\
\hline LR $\operatorname{chi} 2(10)$ & $116.4 * * *$ & & & \\
\hline Prob $>$ chi2 & 0.000 & & & \\
\hline Pseudo R2 & 0.0369 & & & \\
\hline Number of observations & 759 & & & \\
\hline Left-censored observations & 422 & & & \\
\hline Uncensored observations & 337 & & & \\
\hline Right-censored observations & 0 & & & \\
\hline
\end{tabular}

$* * *, * *$ and $*$ is significant at $1 \%, 5 \%$ and $10 \%$ level of statistical error.

Source: own computation, 2021

\section{CONCLUSION AND RECOMMENDATION}

The finding of the study indicates that; more than half of firms that were considered in this study did not purchase the bond for GERD construction. Thereby, there is a justifiable need to exert a stronger and targeted effort to improve the firm's investment in bonds for GERD construction. Based on the finding of this study, the following recommendations are made.

1. Investment in bonds for GERD construction was facilitated by the adoption of innovative technologies. Therefore, government and non-government organizations that engaged with the distribution of technologies should work more to increase the access for each firm by offering it at a reasonable price.

2. Receiving a loan was positively correlated with the firm's decision to purchase and the amount of purchase of bond for GERD construction. Thereby, it is important to increase the provision of a loan by reducing collateral requirements and avoiding complex bureaucratic processes to receive the loan.

3. The existence of female owners, the number of employees, being large in business size and income firms positively contribute to both firms' participation in the bond purchase and amount of their investment on bond purchase for GERD construction. Thereby, it is good if the government and the non-government organization works to empower women to be the owner of firms; and help firms to utilize their potential that leads them to hire more employees, produce high profit and be larger in its size.

Finally, this study strongly recommends further studies on the firm's investment decision on the purchase of 
bond for GERD construction using more recent data, higher sample size, and repeated measures to account for the heterogeneities that are crucial in such studies to come up with precise and practical recommendations.

\section{References}

Abayie, E,Amanor, K., and Frimpong, J. (2011). "The Measurement and Determinants of Economic Efficiency of Microfinance Institutions in Ghana:A Stochastic Frontier Approach", African Review of Economics and Finance, Vol. 2, No. 2,149-166.

ADB., (2021). Country profile. Ethiopia, 2021

Asoga, B.C. Umeh, J.C and Okwoche, V.A., (2012).estimating the determinants of poverty depth among the Peri-urban farmers in Nigeria. Current research journal of social science, 4(3), 201-206.

Brynjolfsson Eland smith M.D., (2000). Frictionless commerce comparison of enter net and conventional, management science, Vol.46 no.4,pp 563-85

Chen, Y .H and I. Hsu., (2009). Website attributes that increase customer purchase intention: A conjoint analysis. Journal of business research

Davidson, W., (2012). IMF Urges Ethiopia to Slow Nile Dam Project to Protect Economy. Retrieved 0612 , 2012 from Bloomberg [online] Available at: http: //www. bloomberg. Com /news /2012- 09-14/ imf-urgesethiopia-to-slow-nile-dam-project-to-protect-economy.html.

Dogan, M., (2013). "Does Firm Size Affect the Firm Profitability? Evidence from Turkey", Research Journal of Accounting and Finance, Vol. 4, No. 4.

Ekvall, G. and J. Arvonen, (1991). 'Change-Centered Leadership: An Extension of the Two-Dimensional Model', Scandinavian Journal of Management, 7, pp. 17-26.

Fisher M.L., J. Krishnan, S. Netessine, (2006). Retail store execution: an empirical study. Working paper.

Gaur Arti1, Julee and Sukijha Sunita, (2011). Difference in Gender Attitude in Investment Decision Making In India, Research Journal of Finance and Accounting, Vol 2, No 12.

Ghura and Goodwin, (2000). Determinants of private investment: a cross-regional empirical investigation, Applied Economics, 32, 1819-1829

Gonzalez, A., and Lamanna, F., (2007). Who Fears Competition from Informal Firms? Policy Research Working Paper Series 4316, World Bank, Washington DC.

Greene, WH., ( 2012). Econometric Analysis $7^{\text {th }}$ Edition. New York: Pearson Hall.

Handiso B. W., (2018). The challenges and Opportunities of the Grand Renaissance Dam for sustainable Energy - Water - Food - Ecosystem services Nexus in Ethiopia., Master thesis in Sustainable Development at Uppsala University, No.2018/30, 43 pp, 30 ECTS/hp.

Howell, J. M. and C. A. Higgins, (1990). 'Champions of Technological Innovation', Administrative Science Quarterly, 35, pp. 317-341.

IEA, (2017). Share of total primary energy supply [Online] accessed June 5, 2018, available at:https://www.iea.org/stats/WebGraphs/ETHIOPIA4.pdf

Kipesha, E.F., (2013). "Impact of Size and Age on Firm Performance: Evidences from Microfinance Institutions in Tanzania", Research Journal of Finance and Accounting, Vol.4, No.5, 105-116.

Makonnen T., (2016). The Imperative of Stepping-up Ethiopian Diaspora's Contribution to Hedase Dam (GERD). London, 16 April 2016

McDonald, J.D. and Moffit, R.A., (1980). The Uses of Tobit analysis. Review of Economics and Statistics, 62: $318-21$

Naudé W., Szirmai, A., (2012). The importance of manufacturing in economic development: Past, present and future perspectives. UNU-MERIT Working Papers, 2012-041, 2012.

Ndikumana, L., (2014). Can Macroeconomic Policy Stimulate Private Investment in South Africa? New insights in to aggregate and manufacturing sector- level evidences. Department of Economics, University of Massachusetts, Amherst

Oliva, R., J.D. Sterman, (2001). Cutting corners and working overtime: quality erosion in the service industry. Management Science 47(7) 894-914.

Powell, M. and Ansic, D., (1997). Gender differences in risk behavior in financial decision making: An experimental analysis, Journal of Economic Psychology, 18, pp.605-628.

Tobin, J., (1958). Estimation of relationship for limited dependent variable. Econometrica, 22: 26-36

Tushman, M. L. and C. A. O’Reilly, (2002). Winning Through Innovation. HBS Press, Boston.

UNDP, (2017). Growing Manufacturing Industry in Ethiopia. A Case Study of Growing Manufacturing Industry in Ethiopia. Presented at the second edition of the International Conference on the Emergence of Africa (ICEA II) from 28th to 30th March 2017, in Abidjan, Cote d'Ivoire.

Verbeek, M., (2004). A Guide to Modern Econometrics $2^{\text {nd }}$ Edition. The Atrium, Southern Gate, Chichester, West Sussex PO19 8SQ, England: John Wiley and Sons Ltd.

Veugelers, R., (2013). Manufacturing Europe's future, Bruegel Blueprint Series, Volume XXI, October. eds. 
Warren, J. H., (2013). Made in America 2.0: 10 Big Ideas for Saving the United States of America from Economic Disaster. Publisher: Xlibris LLC, 2013.

WB, (2020). The World Bank in Ethiopia. Online available. Last Updated: Oct 13, 2020

WB, (2021).World Development Report. World Bank, Washington, D.C, USA.

Westkämper, E., (2014). Towards the Re-Industrialization of Europe: A Concept for Manufacturing for 2030. Springer-Verlag Berlin Heidelberg, 2014

Williams, C. C., and Kedir, A., (2017). Starting-up unregistered and firm performance in Turkey. International Entrepreneurship and Management Journal, 13(3), 797-817.

Wooldridge, J. M. (2002). Econometric Analysis of Cross Section and Panel Data. Cambridge, Massachusetts London, England: The MIT Press. 